\title{
A Divisão de Botânica do Museu Goeldi
}

\section{Paulo B. Cavalcante ( $\left.{ }^{(}\right)$}

Resumo

O autor apresenta uma sintese das atividades da Divisão de Botânica do Museu Goeldi, a partir de 1955 auando este passou à administraçāo do CNPq. Após a fase Goeldi-Huber (1894-1914) coincidente com o início da primeira guerra mundial e a crise que assolou a regiāo, o Museu, que até entăo se projetava internacionalmente nos meios cientificos, entrou em total decadência, paralisando todas as pesquisas botânicas. Nesse período crítico, que perdurou até 1954, as coleçōes do herbário foram em parte destruídas por incúria e falta de recursos. A partir de 1955, sob a administraçăo do $\mathrm{CNPq}$, a Divisão foi reorganizada, o herbário ampliado e modernamente equipado. As coleçōes botânicas subiram de $12 \mathrm{mil}$ para $91 \mathrm{mil}$ amostras e, somente na década de 70 , foram realizadas cerca de 67 escursões de estudos e coletas. A Divisão conta atualmente com 35 pessoas entre pesquisadores e auxiliares, tendo, até o presente, publicado 85 trabalhos.

\section{BREVE HISTÓRICO}

O Museu Paraense Emílio Goeldi teve o seu período de "explendor", na opinião de muitas pessoas, a partir de 1894, quando Goeldi assumiu a sua direção, até 1914, ano em que morreu J. Huber, substituto de Goeldi. O Herbário Amazônico foi fundado por Huber em 1895, tendo como primeiro auxiliar A. Ducke. A partir desse ano tiveram início as explorações botânicas na Amazônia e a circulação do primeiro Boletim do Museu.

Todos os trabalhos de Botânica publicados no antigo Boletim são de autoria de J. Huber. Desses trabalhos destacam-se: a série "Arboretum" $(1900-1906)$ cujo texto é acompanhado de uma visão iconográfica dos mais importantes vegetais espontâneos da região; a série materiais para Flora Amazônica (1897-1907), especialmente sobre Taxonomia, contém quase uma centena de espécies novas e variedades; as Árvores Frutíferas do $\mathrm{Pa}$ rá (1904), trata especialmente da origem e distribuição geográfica das fruteiras cultivadas no

\footnotetext{
(*) - Museu Paraense Emilio Goeldi Belém.
}

ará; Matas e Madeiras da Amazônia (1909), onde o autor resume os mais vastos conhecimentos relacionados com a Botânica Florestal da Região. No período áureo da borracha Huber publicou uma série de trabalhos sobre seringueiras e outras espécies produtoras de borracha $(1897,1904,1907,1910)$.

As publicações Botânicas do antigo Museu, praticamente se encerraram no ano de 1910.

A renúncia de Goeldi, em 1907, a morte prematura de Huber logo seguida do início da primeira guerra mundial, bem como o colapso na economia da região com a queda nas exportações da borracha, afetaram seriamente a vida do florescente Museu. Em 1918, quando Ducke se transferiu para o Jardim Botânico do Rio de Janeiro, o herbário já havia atingido $17 \mathrm{mil}$ amostras (exsicatas) de plantas.

Nos anos que se seguiram, as atividades do Museu ficaram concentradas ao Parque ZooIógico e à Seção de Etnografia. A Seção de Botânica ficou inativa e suas coleções de plantas sofreram sérios danos e quem nos dá ciência dessa deplorável ocorrência é o próprio Adolfo Ducke (1953:39). Segundo esse notável botânico, melhoraram as condições do horto, porém o herbário continuou em abandono. As latas com as amostras de plantas ficaram em local acessível ao público, em prateleiras, muitas vezes abertas e não fechadas. Sem inseticida ou desinfetante qualquer, durante anos, traças invadiram estas latas e comeram-lhes o conteúdo. Segundo, ainda Ducke, em 1946 foi efetuado um inventário nas coleções do herbário, ocasião em que apareceram patentes os irremediáveis prejuízos que os mesmos tinham sofrido em anos de incúria. Verificou-se estrago total ou parcial da maior parte do material pertencente às famílias As- 
clepiadaceae, Borraginaceae, Bignoniaceae, Verbenaceae, Violaceae, Bixaceae, Cochlospermaceae e Compositae; e ainda uma parte das coleções indeterminadas e da coleção Spruce, cedida ao tempo de Huber, pelo Museu Britânico. Por felicidade a coleção típica de Huber escapou da destruição por ter sido transferida para o Jardim Botânico do Rio de Janeiro. Em 1949 Ducke esteve por algum tempo em Belém e nessa ocasião reorganizou o herbário e efetuou um rigoroso expurgo no que restava do mesmo. Poucos anos depois (1955) esse valioso patrimônio científico embora visivelmente desfalcado, foi definitiva. mente salvo em decorrência do convênio fir. mado entre o Governo do Estado e o Conselho Nacional de Pesquisas (CNPq).

\section{A NOVA FASE}

Em 1955 o CNPq designou W.A. Egler para a direção do Museu em sua nova fase e, como botânico que era, assumiu também a chefia da Seção de Botânica, agora transformada em Divisão de Botânica. Com essa posição vantajosa, W. Egler não encontrou dificuldade para reorganizar e dinamizar a referida Divisão. Vale frisar que no início dessa nova fase verificou-se que os livros de registro do herbário indicavam $17 \mathrm{mil}$ amostras de plantas, exatamente o mesmo número deixado por Ducke quando se desligou do Museu em 1918. Entretanto deve-se deduzir, desse total, cerca de $5 \mathrm{mil}$ amostras que foram danificadas, conforme referimos antes.

Com a contratação de técnicos e auxiliares, de comprovada experiência, todas as atividades inerentes ao herbário foram reativadas. Uma das primeiras medidas de relevância da nova diretoria foi restabelecer o intercâmbio científico com instituiçōes congêneres, nacionais e estrangeiras, e os resultados dessa providência foram imediatos e de saldo positivo, não só para a Divisão de Botânica mas para todo o Museu. Agora, sob a égipe do CNPq, as exploraçōes botânicas tornaramse uma constante. Em decorrência do intercâmbio foi elaborado um convênio entre CNPq. New York Botanical Garden e Instituto Agro- nômico do Norte (hoje CPATU-EMBRAPA) para exploração botânica, em conjunto, da área Amapá-Guianas, durante 3 (três) anos (19601962). No primeiro ano os trabalhos se concentraram na região de fronteira, ao longo do rio Oiapoque, com a participação de vários botânicos brasileiros, norte-americanos e europeus. Os trabalhos de campo dessa primeira etapa foram concluídos em três meses.

Em julho de 1961 teve início a segunda etapa do convênio e as explorações foram concentradas em duas áreas diferentes: AraguariAmapari com uma equipe, e o difícil rio Jari, com outra equipe chefiada pelo então diretor Walter Egler. Lamentavelmente os trabalhos de ambas as equipes foram interrompidos antes do tempo previsto devido um trágico acidente nas cachoeiras do rio Jari no qual morreu o diretor Walter Egler. Foi realmente um saldo bastante negativo para o Museu e para toda comunidade botânica.

A terceira e última etapa foi realizada apenas com o pessoal local, na área costeira $\mathrm{e}$ campos do Amapá.

Desse programa de exploração botânica resultou uma volumosa coleção de plantas que foram distribuídas entre os principais herbários nacionais e a vários botânicos taxonomistas de outros países para identificaão.

Não obstante o empenho do CNPq para soerguer e dinamizar os estudos botânicos na região, houve um momento em que tudo, nesse campo, parecia voltar à estaca zero. No curto período de 1957-1963 a regiăo ficou desfalcada de quatro botânicos de renome, em conseqüência de morte natural ou devido a acidentes, além de outros que se transferiram para outros centros, os quais, de certo modo vinham colaborando efetivamente com a Divisăo de Botânica. Esta ficou, pois, restringida unicamente ao seu novo responsável que se considerava ainda iniciante.

Diante de tal esvaziamento tornava-se urgente uma providência para corrigir essa situação e a única solução seria interessar pessoas da região, estudantes de cursos universitários, tendo em vista a formação de um núcleo de jovens que, num futuro próximo, ti- 
vessem condiçōes de prosseguir com a pesquisa botânica da região. O CNPq reconhecendo o alcance desse objetivo não hesitou em proporcionar os recursos necessários com os quais se pode realizar, por volta de 1965, um curso de morfologia e fisiologia vegetal e palinologia, ministrado por professores do sul do país. Os resultados foram altamente satisfatórios, principalmente porque despertou grande interesse entre os participantes, pela pesquisa botânica. A partir daí a Divisão de Botânica passou a receber, em média, 15 estagiários por ano para treinamento em botânica e, como incentivo, passaram a receber bolsa de iniciação científica do CNPq. Parte desses antigos estagiários permanecem na região, na própria Divisão de Botânica, na Universidade ou em outras instituições de pesquisas; alguns já concluíram cursos de doutoramento ou de mestrado.

Até 1961 a Divisão ocupava um prédio antigo. inadequado e em condiçōes extremamen- te precárias; suas paredes cheias de fendas, o teto invadido pelos cupins, constituiam uma séria ameaça, pois podiam desabar na época das grandes chuvas. O herbário ocupava um compartimento de exíguas dimensões e as exsicatas eram arrumadas em prateleiras de compensado, vulneráveis, portanto, a quaisquer perigos, tais como fogo, insetos, etc. (Fig. 1 e 3 ).

Com recursos específicos proporcionados pelo $\mathrm{CNPq}$, o prédio sofreu uma reforma total, com a substituição do teto e maioria das paredes, além de ter sua área consideravelmente ampliada (Fig. 2).

Para completar essa reforma foram adquiridos 128 armários de aço para as coleçōes de plantas e para a xiloteca, ficando o herbário em condições desejáveis de proteção e de consulta (Fig, 4). Com essa sensivel melhoria tornou-se possivel criar dois setores complementares ao herbário - uma xiloteca e uma carpoteca.

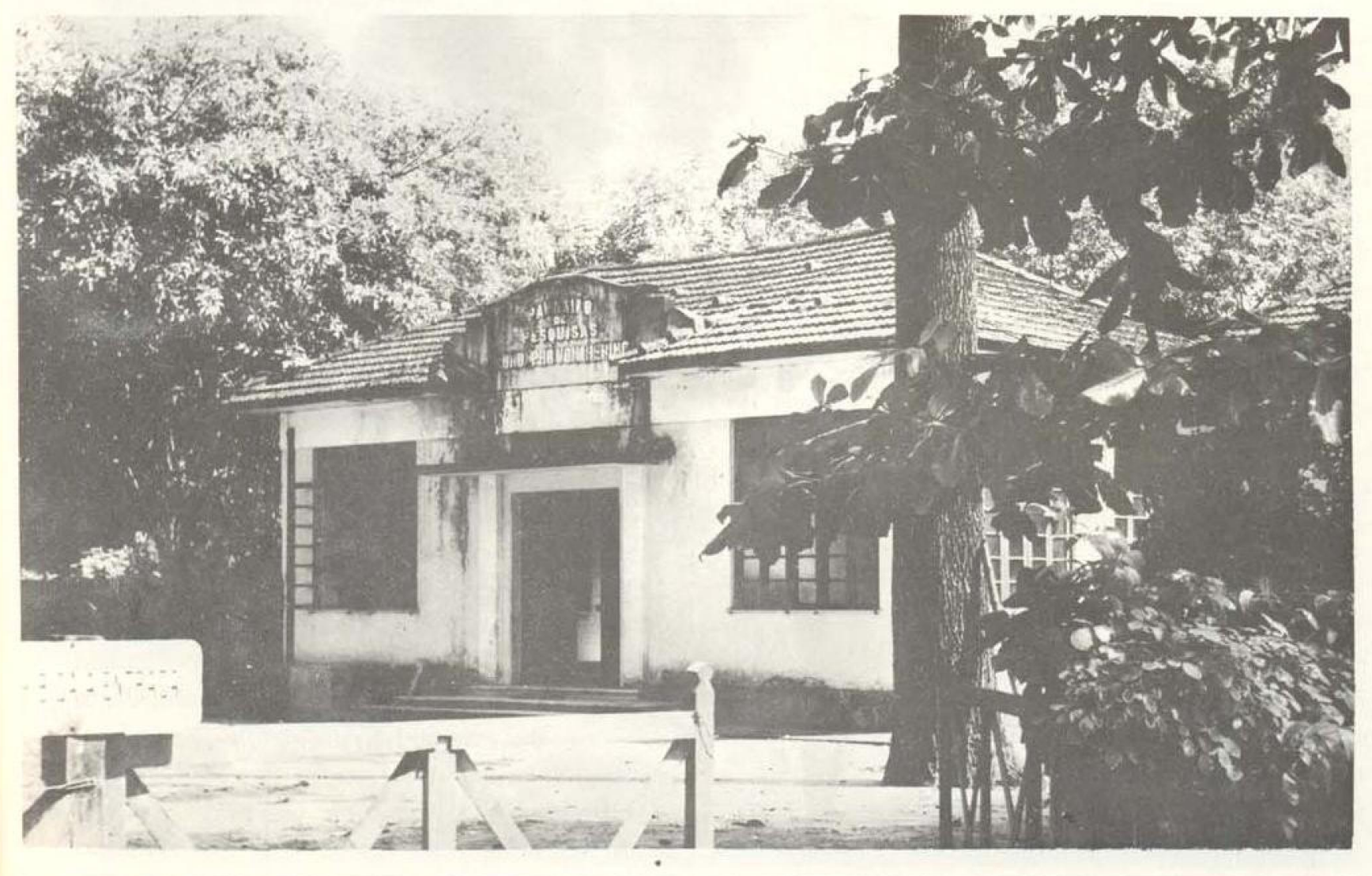

Fig. 1 - Em 1955 a Divisão de Botânica, com seu. herbário, foi instalada neste prédio. 


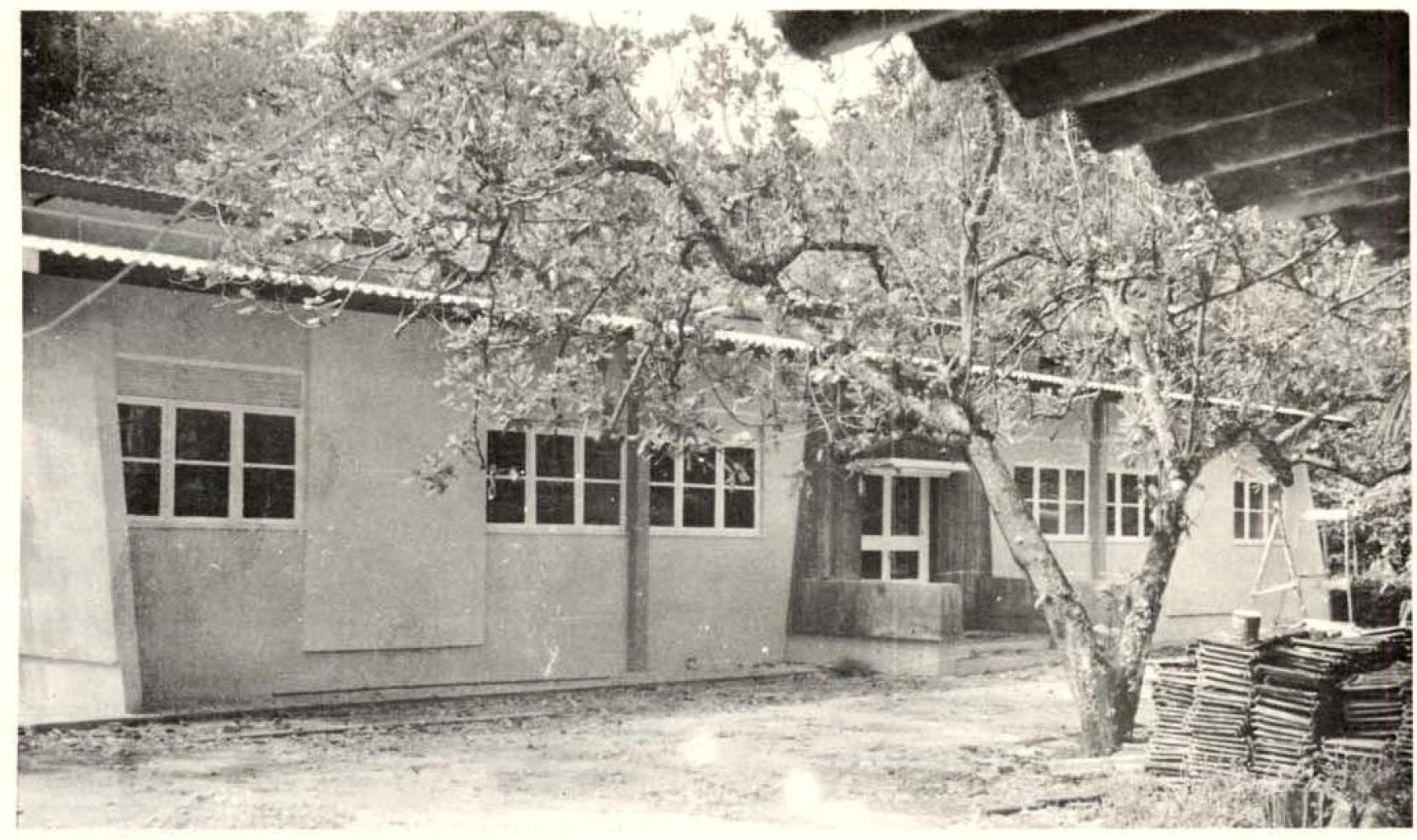

Fig. 2 - O mesmo prédio, reformado e ampliado pelo $\mathrm{CNPq}$ em 1962, hoje sem espaço suficiente para conter coleçōes e pessoal.

A seguir, com a implantação dos grandes projetos do Governo Federal na região (Projeto RADAM e abertura dos grandes troncos rodoviários), a Divisão ampliou e intensificou as explorações botânicas, dada as facilidades de penetração oferecidas durante a execução daqueles Projetos. Utilizando transportes aéreos, terrestres e aquáticos do Projeto RADAM, foi possível visitar e estudar a vegetação das serras Neblina, Aracá, Parecis, Tunui e várias outras localidades ainda não conhecidas, ricas em endemismos e novidades para a ciência.

Em 1975 alguns eventos assinalaram uma fase de Intensas atividades na Divisão de Botánica, sendo o mais importante, a criação do Projeto Flora o qual teve por objetivo o levantamento de todos os dados contidos em exsicatas de herbários para a formação de um Banco de Dados. Para a execução desse projeto - CNPq autorizou a contratação de 11 (onze) botânicos recém-formados de nossas Universidades, bem como coletores e mateiros, desde que o projeto previa grandes explorações botânicas. Estas explorações foram realizadas na base de convênios entre CNPq e a NSF, dos Estados Unidos e, durante sua vigência, foram realizadas cerca de duas dezenas de excursões cobrindo áreas pouco conhecidas da regiăo.

Concluídos os trabalhos de levantamento de dados nos herbários o pessoal de nível superior passou para o quadro de pesquisadores da Divisão, no nivel de Assistente de Pesquisa.

Depois que todos os espécimes identificados do MG tiveram suas informações transportadas para o Banco de Dados os botânicos encarregados do projeto tiveram diminuída a sua carga de atividades de rotina, sobrandoIhes grande parte do tempo para se dedicar especificamente à pesquisa, em parte aperfeiçoando os anteriores dados que haviam sido transportados para as fitas magnéticas. Foi possivel também, desde então, enviar botâni- 
cos que não tinham pós-graduaçấo para os cursos de mestrado e doutoramento, esperando-se assim que dentro de algum tempo, todos os 14 botânicos do $M G$ terăo curso de doutoramento.

$\mathrm{Na}$ nova série do Boletim do Museu, iniciada em 1955, bem como na série avulsa, foram publicados 65 trabalhos e, em revistas de outras instituições, nacionais e estrangeiras, foram publicados 20 trabalhos sobre pesquisas realizadas na Divisăo de Botânica, perfazendo um total de 85 publicações. Desses trabalhos mencionaremos apenas os seguintes: Egler (1960), sobre a fitofisionomia dos campos da regiāo do Ariramba, Oriximiná; Egler (1963). biografia completa de A. Ducke; Cavalcante (1972, 1974, 1979), estudo botânico acompanhado de dados fenológicos e distribuição geográfica de 170 espécies frutíferas da Amazônia; Pires (1976-1978), aborda os tipos de vegetação da Amazônia e os problemas que poderão surgir em conseqüência de seu desequilíbrio ecológico pela interferência humana; van den Berg (1979), estudo taxonômico do gênero Vis. mia, família das gutíferas.

\section{RESERVA BIOLOGICA}

A idéia do Museu possuir uma reserva biológica é muito antiga e vem desde os tempos de Goeldi. Na época deste diretor existiu, de fato, uma reserva na Zona Bragantina tendo, porém, sido logo abandonada em conseqüência da crise econômica da época. Somente em 1979, após cansativas gestōes junto aos setores competentes e graças a compreensão do atual Governo o Museu entrou na posse da Reserva do Acará por meio do Decreto n. ${ }^{\circ} 444$, publicado no D.O. de 07.12.1979. Essa reserva, com uma área de 11 mil hectares, embora algo perturbada em algumas partes, permitirá a implantação de um centro de estudos integrados de ecossistema.

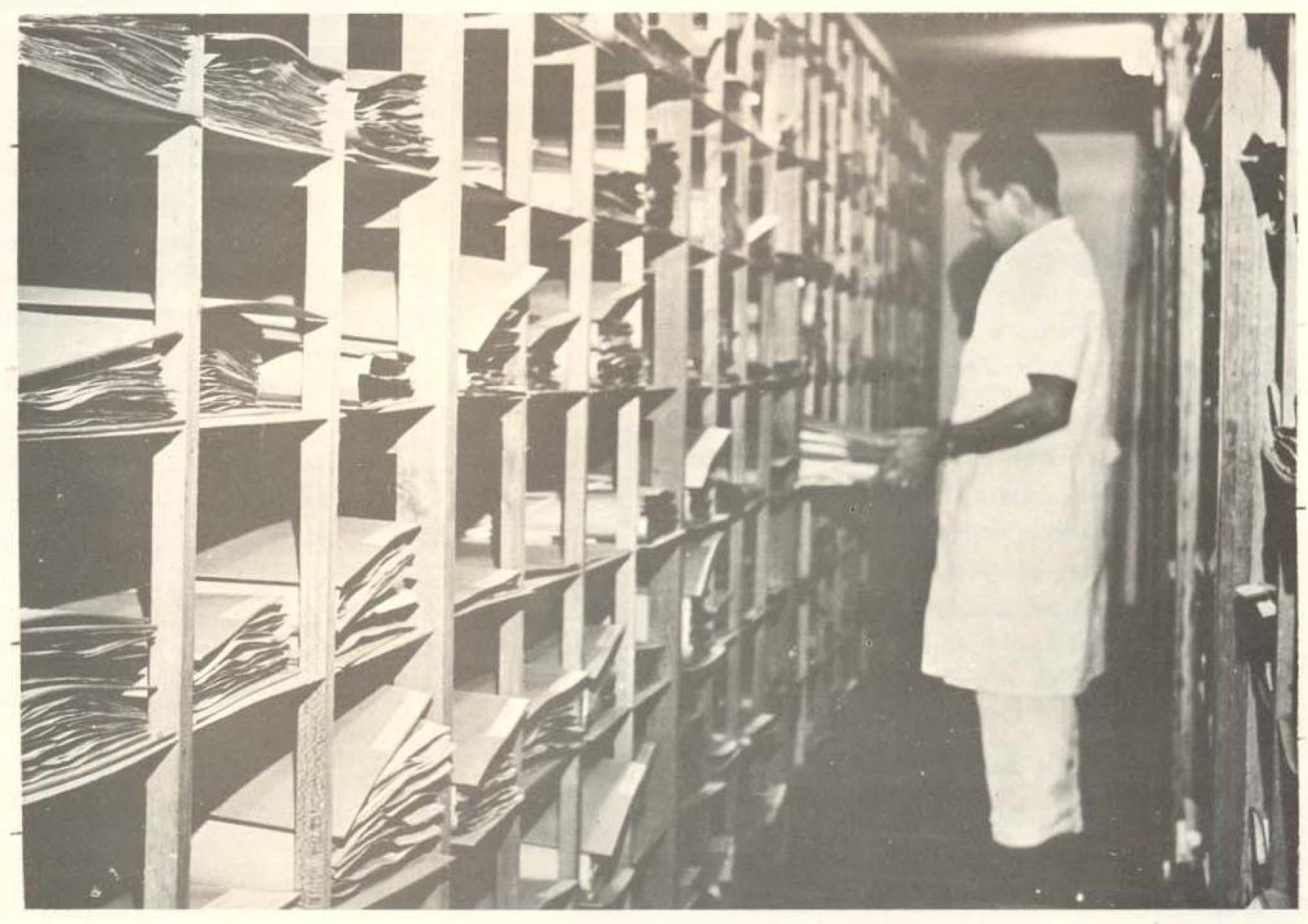

Fig. 3 - Detalhe do herbário, reorganizado em caráter provisório, no início da fase CNPq. 


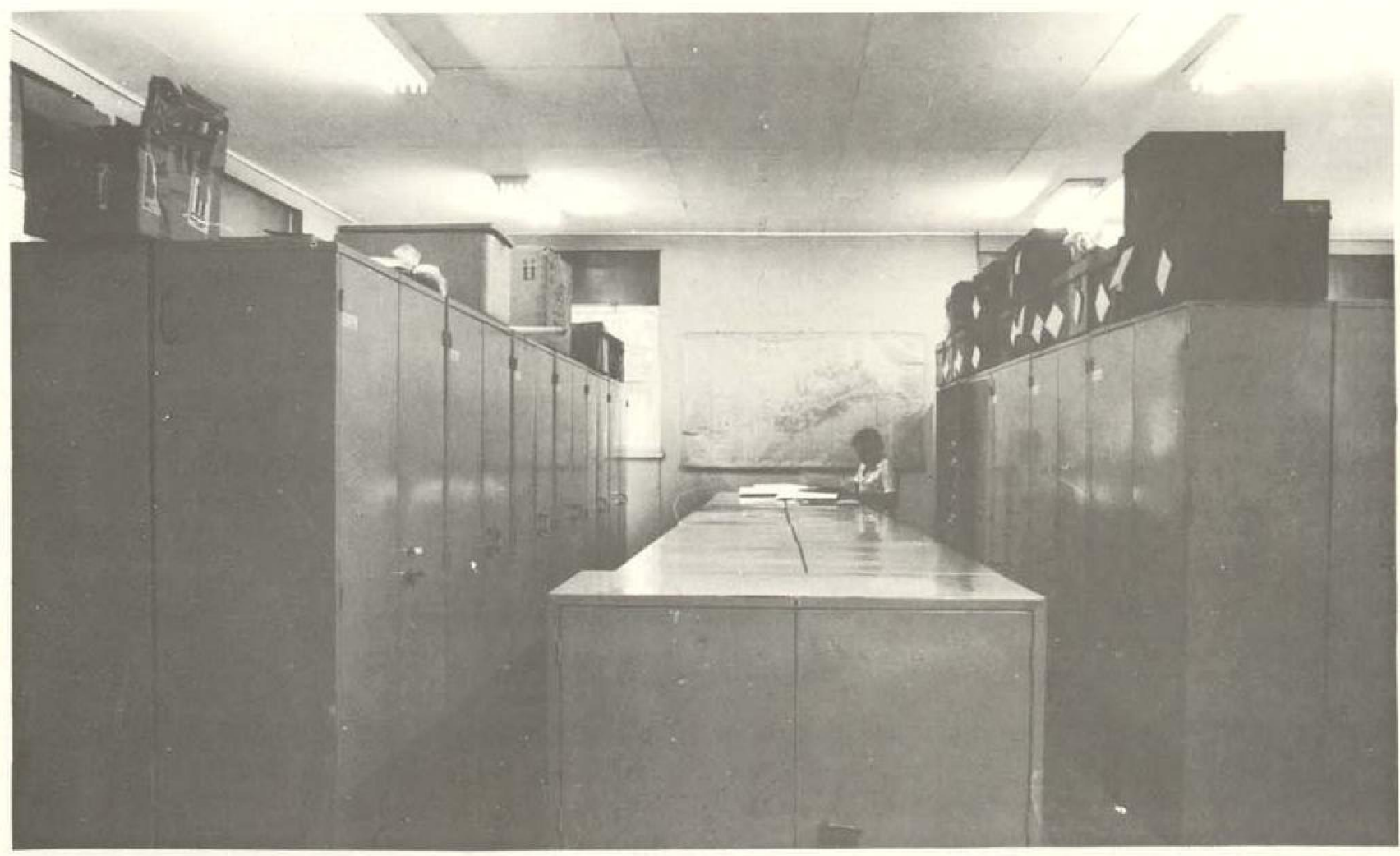

Fig. 4 - Detalhe do herbário atual.

\section{AS EXPLORAC̣ŌES BOTÂNICAS MAIS RECENTES}

De 1970 até o presente foram realizadas cerca de 65 excursōes para exploração botânica, com permanência no campo, de um a três meses em cada excursão, além de outras de menor duração.

Nessas excursões foram realizados estudos de tipos de vegetação, inventários, estudos florísticos, observações ecológicas e, sobretudo coletas de material para herbário, xiloteca e carpoteca além de plantas vivas ou sementes para o horto botânico. As principais excursōes foram as seguintes :

a) EM COLABORAÇÃo COM O PROJETO RADAM

1974 - T. F. Roraima, compreendendo o médio e baixo rio Branco e todos os afluentes desses trechos.

1975 - Amazonas, alto rio Negro, Cucui e serra Tunui.
- Amazonas, Tabatinga médio rio Javari e afluentes do lado Brasileiro.

1976 - T. F. Rondônia, serra dos Pacaás-Novos, onde foi descoberto um pinheiro amazônico (Podocarpus rospigliosii) de origem andina, atualmente cultivado no Horto do Museu Goeldi.

1977 - Mato Grosso, Chapada dos Parecis

1979 - Alto rio Xingu, Rio Dourado.

- Sudoeste de Mato Grosso, Sararé e Parecis.

1980 - Goiás, ilha do Bananal, campos inundáveis.

- Mato Grosso, Paxoréu e limite da mata hileiana e cerrado.

b) EM CONVÊNIO COM O NEW YORK BOTANICAL GARDEN, PARA O PROJETO FLORA

1977 - Pará, Marabá, serra dos Carajás.

- Pará, Rodovia Transamazônica até serra do Cachimbo. 
1978 - Estado do Acre.

1979 - T. F. Amapá, estrada Perimental Norte e rio Oiapoque.

- T. F. Rondônia, chapada dos Parecis.

1980 - Pará, estrada Belém Brasilia, até Goiás.

— Pará-Maranhão, matas de transição.

- Pará, rio Xingu.

c) DO PROGRAMA DO DEPARTAMENTO DE BOTÂNICA

1970 - Pará, serra dos Carajás .

1974 - Pará, Altamira, durante a abertura da rodovia Transamazônica.

1976 - Amazonas, Humaitá.

1977 - Mato Grosso, rio Juruena.

1978 - Amazonas, serra Aracá.

— Rodovia Santarém-Cuiabá.

- Amazonas, serra da Neblina.

1979 - T. F. Roraima, rio Uraricoera.

- Mato Grosso, Aripuanã.

- Pará, serra do Cachimbo.

- Fronteira Brasil-Venezuela, com o apoio da Comissão Brasileira de Limites.

1980 - Amazonas, rio Juruá, com apoio da Petrobrás para correlacionamento de tipos de vegetação e ocorrência de petróleo.

- São Paulo, serra Paranapiacaba.

1981 - Mato Grosso, em colaboração com a SUDHEVEA.

\section{COLABORAÇÃO COM OUTRAS INSTITUIÇÕES}

A Divisão de Botânica vem ultimamente cooperando com outras instituições, principalmente no que diz respeito a criação de novos herbários na região. No momento estão em fase de fundação um herbário na Universida. de Federal do Maranhão e outro no Museu Costa Lima, no Território Federal do Amapá. A Divisão de Botânica do Museu Goeldi vem orientando os responsáveis por esses herbá. rios e ao mesmo tempo fornecendo duplicatas de plantas já identificadas para início de suas coleções.

A Divisão de Botânica do MG, colabora, também, com a EMBRAPA, numa divisão harmônica de trabalho, de vez que a referida Empresa se dedica a assuntos de cunho puramen. te econômico e o Museu à pesquisa básica.

A Divisão tem a seu cargo a grande responsabilidade do estudo botânico da área a ser inundada pela represa da hidrelétrica de Tucuruí. Equipes de botânicos e coletores da Divisão trabalham em regime permanente em levantamento florístico, inventário, coletas. etc.

\section{SITUAÇĀO ATUAL}

Conforme pode-se concluir desse breve resumo, o crescimento da Divisão de Botânica foi incontestável, sobretudo a partir de 1975. Os dados seguintes, referentes apenas ao pessoal e às coleções existentes em 1955 e na época atual, dão uma idéia desse crescimento.

até 1955 em 1981

\begin{tabular}{lcc}
\hline Botânicos & 0 & 14 \\
Estagiários & 0 & 7 \\
Auxiliares & 1 & 13 \\
Exsicatas & $12 \mathrm{mil}$ & $85 \mathrm{mil}$ \\
Xiloteca & 0 & $4 \mathrm{mil}$ \\
Carpoteca & 0 & $2 \mathrm{mil}$ \\
\hline
\end{tabular}

Em razão desse crescimento o espaço fisico tornou-se insuficiente e sem condição para abrigar pessoal e coleções. Daí as providências do $\mathrm{CNPq}$ para construção de novas instalações em área cedida pela EMBRAPA onde já se encontra as edificações prontas 


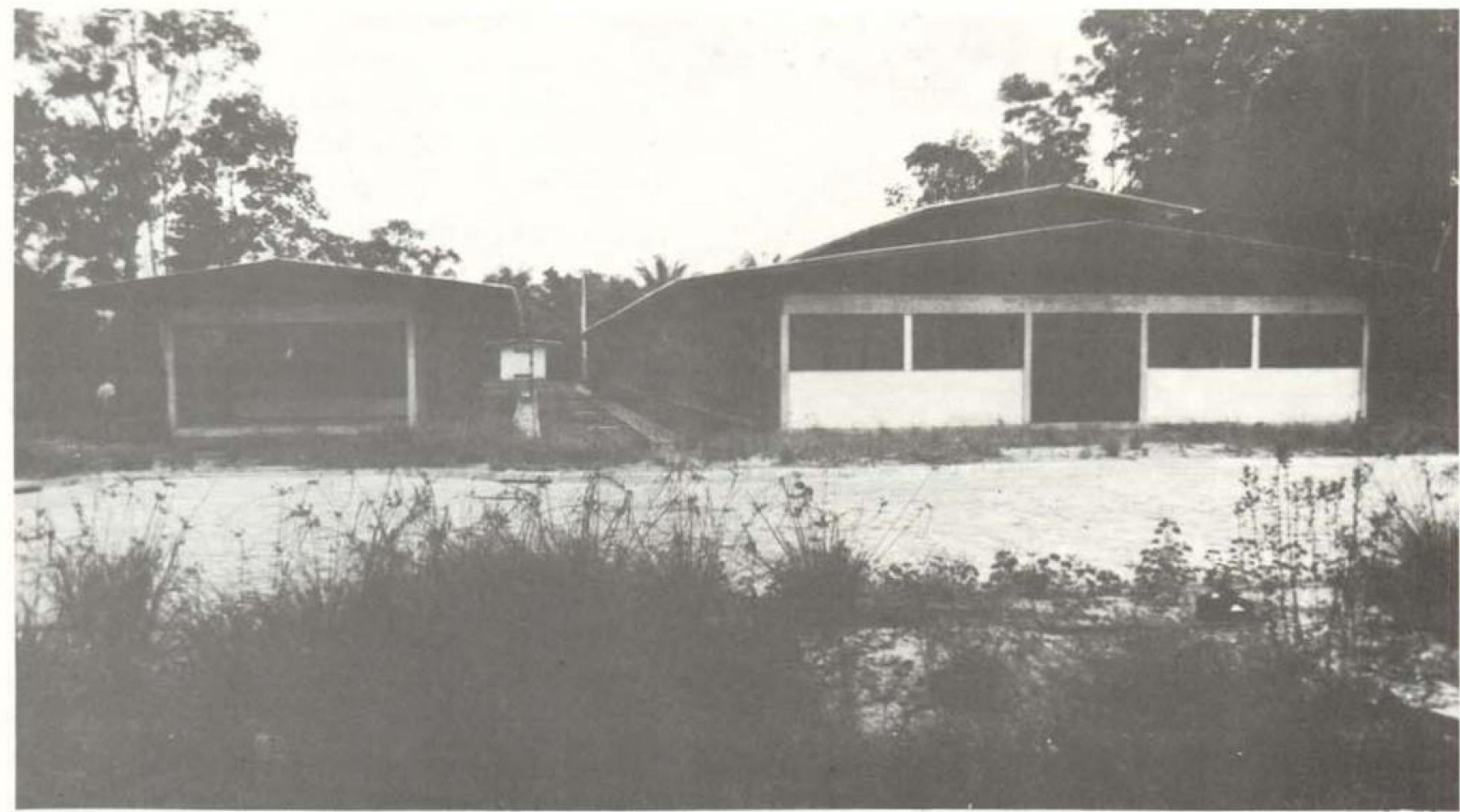

Fig. 5 - Edificações (já concluídas) onde será instalada a Divisão de Botânica, em área adquirida da EMBRAPA, pelo $\mathrm{CNPq}$ : o herbário com $540 \mathrm{~m}^{2}$ será o maior da América do Sul.

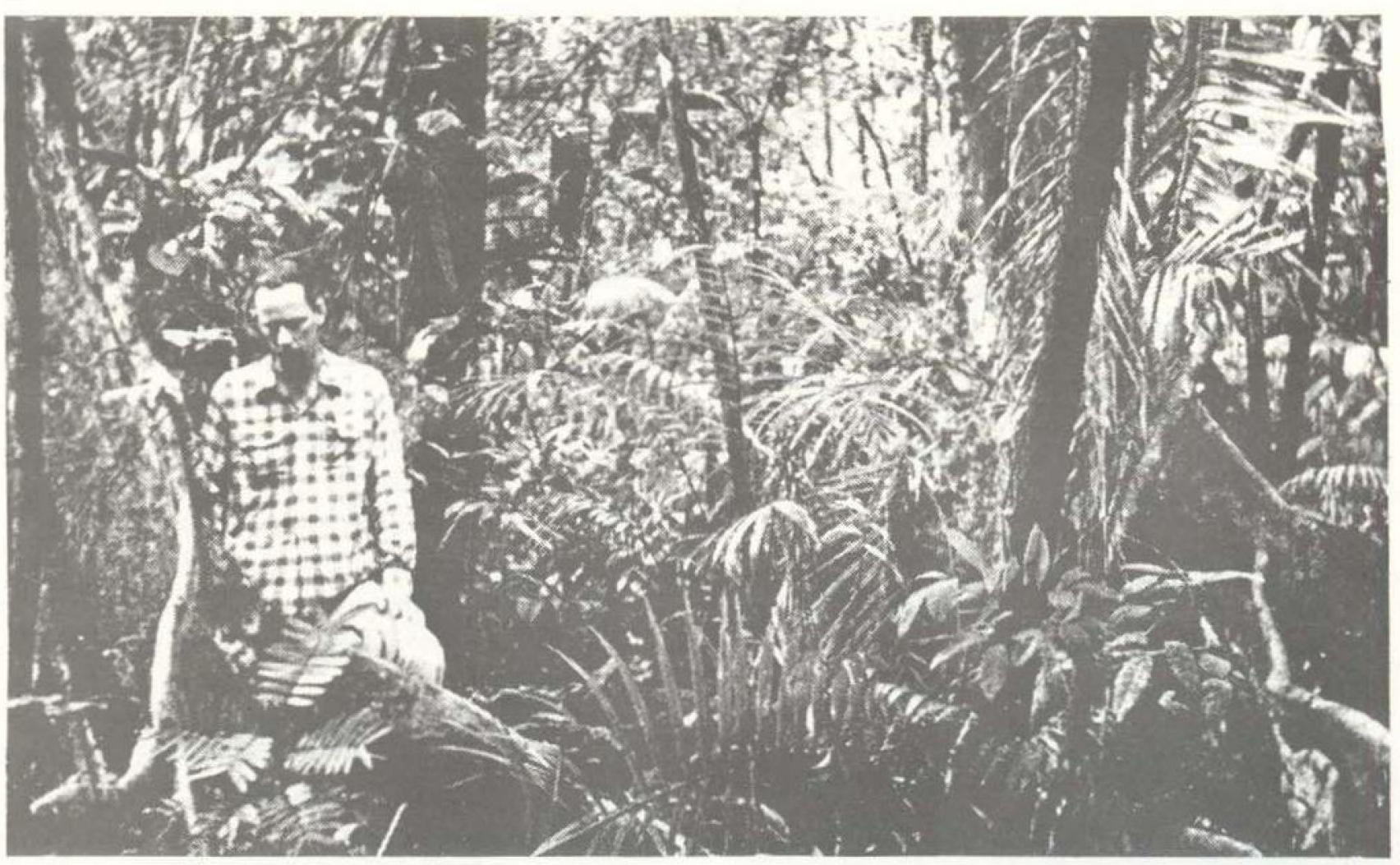

Fig. 6 - Walter A. Egler, botânico, diretor do Museu Goeldi entre 1955-61, morto durante uma excursāo botânica no rio Jari em 28-08-1961. (Foto Aubreville, 1961). 
para serem ocupadas. A área construida, destinada exclusivamente ao setor de Botânica, abrange $2.450 \mathrm{~m}^{2}$, dos quais $540 \mathrm{~m}^{2}$ são destinédos exclusivamente ao herbário, projetado pára receber cerca de 500-600 mil exsicatas (Fig. 5). Dependendo do resultado de um entendimento que o Museu vem mantendo com a EMBRAPA é provável a unificação dos dois herbários destas instituiçōes em um só. Construído com toda a técnica moderna e dispondo de armários de aço à prova de quaisquer danos, a região terá, em breve, o maior e mais moderno herbário da América do Sul.

Em conseqüência do alto conceito que atualmente desfruta nos meios científicos o Departamento de Botânica vem sendo freqüentemente solicitado por outras instituiçōes a prestar colaboraçäo, quer em assunto puramente botânico ou sobre meio ambiente, preservação, participação em debates, etc.

\section{SUMMARY}

The activities of the Department of Botany of the Museu Goeldi are considered in this memoir, beginning in 1955 when the administration of the Museu became the responsability of the Conselho Nacional de Desenvolvimento Científico e Tecnológico (CNPq). Since 1914, with the death of the botanist J. Huber, Botanical research at the Museu in the former Botany Section had come to a standstill, and the herbarium collection of plant specimens suffered serious losses due to its state of virtual abandonment and to the lack of resources for its curation

In 1955, with the entry of the CNPq into the Museu by virtue of a bilateral agreement with the government of the State of Pará, the entire collection of the herbarium consisted of only 12,000 plant specimnes in the care of a part-time curator, in that same year, the botanical collection was completely reorganized and botanical expeditions were begun. Botanical research was reiniciated, and the research staff in Botany was gradually expanded to the presente level: 35 people, including the botanists, research students and techninicians. Presently, the Department of Botany holds 91,000 botanical specimens, comprising the colletctions of pressed plants, woods, and fruits. During the decede of the 1970s, about 65 excursions were conducted most of wich involved 30 to 90 days in the field.

\section{REFERENCIAS BIBLIOGRAFICAS}

BERG, E. v.d.

1979 - Revisăo das espécies brasileiras do gênero Rheedia L. (Guttiferze). Acta Amaz., Manaus, 9 (1): $43-74$, il.

CAVALCANTE, Paulo B.

1972 - Frutas Comestiveis da Amazônia I. Publ. Avulsas Mus. Pa. Emilio Goeldi, Belém, 17. 84 p. il.

1974 - Frutas Comestiveis da Amazônia II. Publ. Avulsas Mus. Pa. Emilio Goeldi, Belém, 27. 73 p. il.

1979 - Frutas Comestiveis da Amazônia III. Publ Avulsas Mus. Pa. Emilio Goeldi, Belém, 33. 61 p. il.

DUCKE, A.

1953 - O herbário amazônico do Museu Paraense em 1950. B. tec. IAN, 28: 39-44.

EGLER, W.A.

1960 - Contribuições ao conhecimento dos campos da Amazônia. I - Os campos do Ariramba. B. Mus. Pa. Emílio Goeldi, n, ser Bot., 4. 36 p. il.

1963 - Adolpho Ducke - traços biográficos, via. gens e trabalhos. B. Mus. Pa. Emílio Goeldi, n. ser. Bot., Belém, 18. 129 p.

HUBER, Jacques

1897 a - Os nossos conhecimentos atuais sobre as especies de seringueiras. B. Mus. Goeldi, Hist. Nat. Ethnogr., Belém, 2: 250-253.

1897b- Materiais para a flora amazonica I. Lista das plantas colligidas na liha de Marajó. B Mus. Goeldi, Hist. Nat. Ethnogr., Belém. 2: 288-322.

1900 - Observaçōes sobre as arvores de borracha da regiẫo amazonica. B. Mus. Goeldi, Hist. Nat. Ethnogr., Belém, 3: 345-369.

1900/06 - Arboretum Amazonicun I. Iconografıa dos mais importantes vegetais espontâneos e cultivados da Regiãu Amazonica. Belếm, Museu Goeldi. 40 p. il.

1904 - Notas sobre a patria e a distribuição geo. graphica das arvores frutiferas do Pará. B. Mus. Goeldi, Hist. Nat. Ethnogr., Belém. 4: $375-406$.

1906 - Arvores de borracha e de balata da regiãa amazonica. Especies do gênero Sapium. B Mus. Goeldi, Hist. Nat. Ethnnograf., Belérn, 4: 415-437.

1907 - A Hevea benthamiana como fornecedora de borracha ao norte do Amazonas. B. Mus. Goeldi, Hist. Nat. Ethnograf., Belém, 5: 242-248. 
1908 - Materiais para a flora amazonica VII. Plan. tas Duckeanae austro-guyanenses. B. Mus Goeldi, Hist. Nat. Ethnogr., Belém, 5: 294-436.

1909 - Mattas e madeiras amazonicas. B. Mus Goeldi, Hist. Nat. Ethnogr., Belém, 6: 91225.

1910 - Novas contribuiçōes para o conheciments do gênero Hevea. B. Mus. Goeldi, Hist Nat. Ethnogr., Belém, 7: 199-281.

PIRES, J. Murça

1976 - Aspcetos ecológicos da floresta amazônica. Congresso Brasileiro de Florestas Tropicais, 2, Mossoró. 1976. Anais... Mossoró p. 235-287. il. (coleção mossoroense, 65) (separata)

1978 - The forest ecosystem of the Brasilian Ama. zon: description, functioning and research needs. In: TROPICAL FOREST ECOSYSTEMS Paris, UNESCO/UNEP/FAO. 683 p. (natural resources research, 14) p. 608-627.

PIRES, J. Murça \& PRANCE, G.T.

1977 - The Amazon forest: a natural heritage to be preserved. In: EXTINCTION is forever: procedings of a Symposium held at the New York Botanical Garden, May 11-13, 1976. Ed. G.T. Prance and T.S. Elias, New York Botanical Garden. 437: p. 158-194. il. 